\title{
Assises nationales de l'Éducation à
} l'Environnement

11 au 13 février 2000 - Lille (France)

Louis Goffin

\section{(2) OpenEdition \\ Journals}

Édition électronique

URL : http://journals.openedition.org/ere/7008

DOI : $10.4000 /$ ere.7008

ISSN : 2561-2271

Éditeur

Centr'ERE

Référence électronique

Louis Goffin, «Assises nationales de l'Éducation à l'Environnement », Éducation relative à

l'environnement [En ligne], Volume 2 | 2000, mis en ligne le 15 septembre 2000, consulté le 17 avril

2021. URL : http://journals.openedition.org/ere/7008 ; DOI : https://doi.org/10.4000/ere.7008

Ce document a été généré automatiquement le 17 avril 2021. 


\title{
Assises nationales de l'Éducation à l'Environnement
}

\author{
11 au 13 février 2000 - Lille (France)
}

Louis Goffin

1 Du 11 au 13 février dernier se sont déroulées à Lille les premières Assises nationales de l'Éducation à l'Environnement. Elles étaient organisées par un collectif fort d'une cinquantaine d'organisations et de nombreux partenaires associés: État, collectivités territoriales, entreprises, fondations. Le succès fut au rendez-vous, en raison du grand nombre de participants (1200 présents et 400 qui n'ont pu être acceptés), du sérieux de la préparation antérieure (12 rencontres régionales très mobilisatrices), de la qualité de l'organisation lilloise et enfin de la richesse des exposés, des échanges, des débats vécus. Visiblement, la France est prête à accueillir Planèt'ErE II l'année prochaine, faisant suite au Planèt'ERE I de Montréal en 1997.

2 Ayant participé à ces assises en tant que représentant du monde scientifique et du milieu associatif, je me permets de livrer ici quelques réflexions personnelles, reflet de ma perception de l'événement. Les voici brièvement énoncées: l'appui des autorités politiques françaises au plus haut niveau est assuré, comme l'ont montré les interventions des ministres Allègre et Voynet. À cet égard, on notera qu'outre l'Éducation nationale et l'Environnement, d'autres ministères apportent leur soutien effectif à la promotion de l'ErE, comme l'Agriculture, la Jeunesse et les Sports, la Ville, etc. Par ailleurs, les Collectivités territoriales (Régions, Départements, Communes) sont également impliquées. Les publics concernés par l'ErE sont diversifiés: entreprises, syndicats, pouvoirs publics à tous les niveaux, monde agricole, groupements professionnels, bureaux d'études et consultantes, médias, ainsi qu'une plus grande variété d'associations, et bien sûr, le monde scolaire et universitaire, mais aussi celui de la formation professionnelle.

3 Les thématiques discutées ont convergé en trois "groupes structurants » qui me semblent très pertinents:

- la mise en oeuvre de l'ErE à l'échelle des territoires de vie;

- les acteurs de l'ErE à travers les nécessaires institutionnalisations; 
- les valeurs et principes de l'ErE au service du développement durable.

4 Sur ce dernier point, on n'a pas évité les discussions de pertinence conceptuelle ni les inévitables démystifications de la réappropriation par l'économie des principes du développement durable!

Pour terminer, je mettrai encore en évidence l'excellent esprit d'accueil et d'écoute de l'autre, indispensable aussi à la promotion de l'ErE, qui régnait à Lille. Bref, une manifestation pareille a de quoi vous rendre le moral et vous faire repartir sur des chemins que nous savons difficiles.

\section{AUTEUR}

\section{LOUIS GOFFIN}

Directeur de la Fondation Universitaire Luxembourgeoise et Président du Réseau IDée 